\title{
INFLUÊNCIA DOS MÉTODOS DE CONTROLE DA LAGARTA-DO-CARTUCHO SOBRE O DESENVOLVIMENTO E PRODUÇÃO DE MILHO.
}

\author{
Jailma Rodrigues dos SAntos ${ }^{1}$, Ana Gabriela de Freitas Maia ${ }^{1}$, \\ Andreza FERreira da COSTA ${ }^{1}$, MAURício SEKIGUCHI DE GOdOY ${ }^{2}$, \\ RAIMUNDO IVAN REMÍGIO SILVA ${ }^{1}$ \\ ${ }^{1}$ Instituto Federal de Educação, Ciência e Tecnologia do Ceará - IFCE \\ ${ }^{2}$ Universidade Federal Rural do Semiárido - UFERSA \\ <jailmars1234@gmail.com><anagabi1941@ hotmail.com><andreza121.af@gmail.com> \\ <msdgodoy@ufersa.edu.br><ivanremigio@ifce.edu.br> \\ DOI: <https://doi.org/10.21439/conexoes.v14i4.1471>
}

\begin{abstract}
Resumo. A cultura do milho tem como praga-chave a Spodoptera frugiperda, acarretando nível de dano econômico. Objetivou-se com o trabalho avaliar o crescimento da planta e a produção do milho-verde após aplicação de técnicas controle da lagarta-do-cartucho. O experimento foi conduzido a campo com o milho híbrido Agroceres (AG 1051) em consórcio com feijão "paulistinha”. Utilizou-se delineamento inteiramente casualizado com 4 repetições, com os tratamentos (TI = Lannate BR + Certero; TII = Bacillus thuringiensis; TIII = fertilizante Matrix com poder de inseticida e TIV = água - testemunha). Estudou-se os estádios de crescimento da cultura, aos 45 e 70 dias após a emergência (DAE) e produção. Para as fases de crescimento aos 45 e 70 DAE, a altura da planta e o número de folhas verdes não diferiram. Havendo diferença, apenas aos 45 DAE, para área foliar e diâmetro do colmo, sobressaindo TI e TII dos demais. $\mathrm{Na}$ avaliação de produção, não foi constatada diferença estatísticas entre os tratamentos. Concluiu-se que os controles químico e biológico apresentaram melhores respostas para área foliar e diâmetro do colmo no crescimento das plantas aos 45 DAE. Nas variáveis de produção todos os tratamentos se comportaram de forma igualitária, mostrando que as características padrões não foram afetadas.
\end{abstract}

Palavras-chaves: Controle biológico. Controle químico. Spodoptera frugiperda.

\begin{abstract}
The maize crop has as pest-key to Spodoptera frugiperda, causing economic damage level. The objective of this work was to evaluate the growth of the plant and the production of green corn after application of technical control of fall armyworm. The experiment was conducted in the field with the hybrid maize Agroceres (AG 1051) in consortium with beans "paulistinha." It was used a completely randomized design with 4 replications, with treatments $(\mathrm{TI}=$ Lannate $\mathrm{BR}+$ Certero; TII = Bacillus thuringiensis; TIII = fertilizer Matrix with power of insecticide and TIV = water - witness). We studied the crop growth stadiums, at 45 and 70 days after emergence (DAE) and production. For the phases of growth to 45 and 70 DAE, plant height and the number of green leaves did not differ. There is a difference, only to 45 DAE, for leaf area and stem diameter, with TI and TII of others. In the evaluation of production, there was no statistical difference among the treatments. It was concluded that the chemical and biological controls presented better responses to leaf area and stem diameter in the growth of plants at $45 \mathrm{DAE}$. In the variables of production all treatments behaved equally, showing that the characteristics patterns were not affected.
\end{abstract}

Keywords: Biological control. Chemical control. Spodoptera frugiperda. 


\section{INTRODUÇÃO}

O milho (Zea mays L.) é o cereal mais cultivado e consumido no Brasil, com aumento no consumo de $1,5 \%$ ao ano (OECD, 2015). A área de cultivo é de 15.417.876 hectares e a produção de 80,9 milhões de toneladas, sendo que o Nordeste é responsável por aproximadamente $10 \%$ do milho produzido no Brasil (IBGE 2016).

Segundo dados da Companhia Nacional de Abastecimento (CONAB), a região Nordeste conseguiu atingir uma produção na safra 2015/2016 de 2425,2 mil toneladas (CONAB, 2016). A importância econômica do milho é caracterizada pelas diversas formas de sua utilização, que vão desde a alimentação animal até a indústria de alta tecnologia (DUARTE et al., 2010).

Durante seu desenvolvimento e crescimento, as plantas de milho são atacadas por diversas espécies de insetos, desde semeadura à colheita, prejudicando sua produtividade. Sendo que a lagarta-do-cartucho (Spodoptera frugiperda) (J. E. Smith, 1797) (Lepidoptera: Noctuidae) é a praga mais prejudicial, que ataca tanto na fase vegetativa quanto na reprodutiva, gerando nível de dano econômico à cultura, tornando-se a pragachave, visto que no Brasil já gerou danos anuais de mais de 400 milhões de reais, atingindo uma redução de até $60 \%$ de produtividade, a depender da cultivar e da época do ataque (ROSA, 2011).

O Manejo Integrado de Pragas (MIP) é um dos fatores que merece destaque no sistema de produção do milho (CHAVES et al. 2012), definido como o uso de várias técnicas de controle de insetos, tendo como objetivo, além de preservar e aumentar os fatores de mortalidade natural, manter a população da praga-alvo em níveis abaixo daqueles capazes de causar dano econômico (EMBRAPA, 2013). Estas medidas reduzem o número de aplicações de inseticidas químicos e visam aumentar o sucesso do controle biológico (PEREIRA, 2007).

O controle químico ainda é o mais utilizado para o controle da lagarta-do-cartucho, com um amplo número de inseticidas registrados (MAPA, 2016), no entanto, o uso do químico está se tornando limitante pelo seu mau uso, ocasionando resistência às pragas, e na maioria das vezes, não são seletivos aos inimigos naturais.

O controle biológico vem ganhando destaque no uso de entomopatogênicos no manejo de pragas agrícolas. Considerado um dos métodos mais seguro aos humanos e ao meio ambiente. Destacando-se a bactéria $B a$ cillus thuringiensis Berliner, 1911 (Eubacteriales: Bacillaceae) no controle de Lepidopteros (GALZER; FILHO, 2016).

Portanto o presente trabalho tem como objetivo ava- liar o crescimento da planta e a produção do milhoverde após aplicação de técnicas para o controle da lagarta-do-cartucho.

\section{MATERIAIS E MÉTODOS}

O experimento foi conduzido na Unidade de Ensino, Pesquisa e Extensão (UEPE), do Instituto Federal de Educação, Ciência e Tecnologia do Ceará (IFCE), na Chapada do Apodí, no município de Limoeiro do Norte, Ceará, de coordenadas geográficas $5^{\circ} 06^{\prime} 38^{\prime \prime}$ de latitude Sul, 37 $52^{\prime} 21$ ' de longitude a Oeste de Greenwich e altitude de $143 \mathrm{~m}$. O clima da região é semiárido, com as condições climáticas caracterizadas por médias anuais de umidade relativa do ar $(62 \%)$, precipitação pluvial $(772 \mathrm{~mm})$ e temperatura $\left(28,5^{\circ} \mathrm{C}\right)$, sendo o trimestre março-maio, o período de maior precipitação e o período julho-dezembro o mais seco (DNOCS, 2015).

A semeadura foi realizado no dia 16 de setembro de 2015, utilizando o milho o híbrido AG 1051 (Agroceres) em sistema consorciado com feijão "paulistinha". $\mathrm{O}$ espaçamento para a cultura do milho foi de $0,80 \mathrm{x}$ 0,27 e para o feijão foi de $0,80 \times 0,70 \mathrm{~m}$, totalizando respectivamente uma população de 40.000 e 3.000 plantas ha-1. A área experimental continha irrigação por pivô central (a lâmina de água era de acordo com a leitura do tanque classe A do dia, pela estação experimental), tendo a parcela $650 \mathrm{~m}^{2}$ de área útil e bordadura de 242 $\mathrm{m}^{2}$. A recomendação da adubação se deu a partir da análise de solo do local do experimento (Tabela 1 ).

$\mathrm{O}$ delineamento experimental foi o inteiramente casualizado. Os tratamentos foram: TI = inseticida Lannate $\mathrm{BR}^{\circledR}+$ Certero ${ }^{\circledR}$; TII = bactéria Bacillus thuringiensis; TIII = fertilizante Matrix com poder de inseticida e TIV = aplicação de água - testemunha com quatro repetições, totalizando 16 parcelas experimentais. Foram avaliados os estádios de crescimento da cultura, detalhadas mais adiante, aos 45 dias e 70 dias, e produção.

Para tomada de decisão do controle da praga, realizou-se o monitoramento da $S$. frugiperda, através de levantamento convencional do grau de dano nas plantas, adotando-se uma escala subjetiva com variação de 0 a 6, proposta e adaptada de Davis, Williams e Wiseman (1989), sendo: $0=$ isenta de dano; $1=$ leves raspados $(<1 \mathrm{~cm}) ; 2=$ raspados grandes $(\geq 1 \mathrm{~cm}) ; 3=$ pequenos furos nas folhas; 4 = cartucho levemente danificado (raspados e pequenos furos); 5 = cartucho moderadamente danificado (furos irregulares $>1 \mathrm{~cm}$ ); $6=$ cartuchos severamente danificados. O nível de controle é alcançado quando, cerca de $20 \%$ das plantas de milhos expressam o sintoma de "folhas raspadas" (FANCELLI; NETO, 2000). 

MILHO

Tabela 1: Análise da fertilidade do solo da área do experimento.

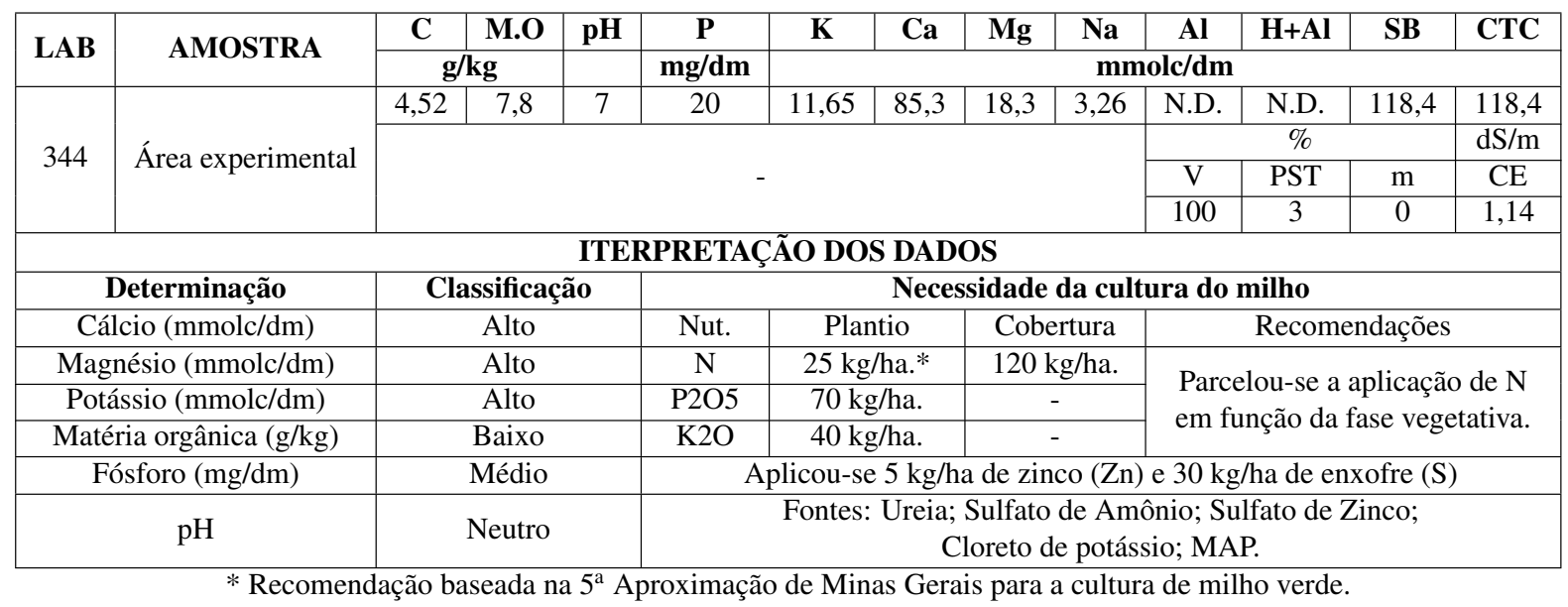

Foram avaliadas 20 plantas por parcela distribuídas em quatro pontos equidistantes de no mínimo $6 \mathrm{~m}$, obtidas por caminhamento em "ziguezague". Analisou-se cinco plantas aleatórias por ponto, totalizando 80 plantas analisadas para cada tratamento. De acordo com a porcentagem do grau de dano, foram feitas quatro amostragens convencionais em intervalos de três dias, iniciando-se a partir do primeiro dia após emergência (DAE), para a tomada de decisão, sendo a aplicação dos tratamentos realizada com base no monitoramento.

No décimo DAE, iniciou-se a aplicação das quatro diferentes técnicas de controle de $S$. frugiperda, nas diferentes parcelas experimentais, sendo: 1) o tratamento I da mistura de $0,6 \mathrm{~L} /$ Lannate ${ }^{\circledR}$ p.c./ ha $+0,1 \mathrm{~L} /$ Certero p.c./ ha, conforme dosagem utilizada pelos produtores do Vale do Jaguaribe - CE; 2) O tratamento II utilizou Agree $\mathrm{BR}^{\circledR}$ (B. Thuringiensis) na dosagem de $500 \mathrm{~g}$ de p.c./ha; 3) O tratamento III, aplicação de $0,5 \mathrm{~L} / \mathrm{ha}$ Phyto-Medicinais (Matrix ${ }^{\circledR}$ da empresa Global Crops); 4) Tratamento IV aplicação de 200 L/ha de H2O (testemunha). As aplicações foram realizadas com pulverizador costal manual, da fase emergência (VE) até a fase de pendoamento (VT) do milho, dentro do período de 45 DAE, no total foram realizadas quatro aplicações.

Para verificação do controle da lagarta-do-cartucho no crescimento da cultura do milho e sua produção, realizou-se após cada aplicação dos tratamentos, avaliações convencionais do grau de dando nas plantas da mesma forma da amostragem convencional, assim como a presença e ausência dos inimigos naturais na área.

Para a avaliação dos estádios de crescimento, escolheram-se aleatoriamente cinco plantas por parcela, avaliando número de folhas verdes; altura da planta $(\mathrm{cm})$, diâmetro do colmo $(\mathrm{cm})$; e a área foliar (AF em $\mathrm{cm}^{2}$ obtida da média das folhas 3, 4 e 5) Para se determinar a AF, utilizou-se o produto do comprimento máximo do limbo $(\mathrm{C})$ pela a largura máxima perpendicular à nervura principal do limbo foliar $(\mathrm{L})$ por um fator de correção de 0,75 (AF = C x L x 0,75), de acordo com Elings (2000). E para variável produção foram analisadas: número de espiga por planta; comprimento longitudinal e diâmetro da espiga com palha e sem palha em $\mathrm{cm}$, com auxílio de um paquímetro; peso da espiga com palha e sem palha em g, com auxílio de uma balança analítica; número de fileira e número de grãos por espiga.

Os dados obtidos foram submetidos ao teste de normalidade de SHAPIRO-WILK $(\mathrm{p}<0,05)$. Os dados com normalidade e homogeneidade, foram transformados quando necessário para arco seno de $\log 10$ ou arco seno SQRT $(X+0,5)$, e submetidos à análise de variância (ANOVA), tendo as médias separadas pelo teste de Tukey $(\mathrm{p}<0,05)$, utilizando o software livre ASSISTAT 7.7 Beta (SILVA, 2014).

\section{RESULTADOS E DISCUSSÕES}

Considerando a amostragem convencional para a tomada de decisão, após 10 dias da emergência das plântulas de milho, os tratamentos I, II, III e IV obtiveram grau de dano de $14 \%, 23 \%, 15 \%$ e $20 \%$, respectivamente, sendo que TII e TIV apresentaram raspagem e pequenos furos (notas entre 1 e 3), atingindo dessa forma nível de controle. Segundo Fancelli e Neto (2000), o nível de controle é alcançado quando cerca de $20 \%$ das plantas de milho expressam o sintoma de "fo- 
lhas raspadas". Vale ressaltar que terminada todas as aplicações dos tratamentos, no $45^{\circ}$ DAE, após 72 horas a nota do grau de dano para cada tratamento foi de 2,76, 4,01, 4,30 e 4,05 para TI, TII, TIII e TIV, respectivamente. Dessa forma, pode-se mensurar o impacto do dano da $S$. frugiperda no desenvolvimento e produção da cultura do milho, em função do método de controle.

Dentre os itens avaliados da fenologia da planta, verificou-se que a altura das plantas não apresentou diferença estatística entre os tratamentos aos 45 e 70 dias, variando de 135,85 a 153,5 e de 177,95 a $215,4 \mathrm{~cm}$, respectivamente (Tabela 2). Resultado aproximado foi encontrado por Rocha (2008) e Barbosa et al. (2012). Ao estudarem as características agronômicas de cultivares de milho, dentre elas a AG 1051, constataram altura média das plantas de 209 e $224 \mathrm{~cm}$, respectivamente.

Para o número de folhas fotossintetizantes ativas na planta, não houve diferença estatística entre os tratamentos para ambos os períodos de avaliação (Tabela 2). Resultados semelhantes foram encontrados por Cruz (2013) ao estudar características morfofisiológicas de plantas e produtividade do milho em diferentes anos, obteve no primeiro ano número médio de 14 folhas e no segundo ano 13 folhas.

O parâmetro área foliar aos 45 DAE mostrou que o TI foi diferente significativamente $(p>0,05)$ do TIII e TIV, no entanto o TII se apresentou indiferente em relação aos tratamentos supracitados. O TI proporcionou maior área foliar decorrente sua maior eficiência no controle da $S$. frugiperda, comprovado pela avaliação do grau de dano, apresentando uma nota de 2,76, onde os demais tratamentos obtiveram nota de 4,01, 4,30 e 4,05 para TII, TIII e TIV, respectivamente. A maior produção de área foliar proporciona as plantas algumas vantagens, como maior tempo de aproveitamento da energia solar e maior oferta de fotoassimilados durante todo o ciclo, proporcionando maior produção de biomassa e grão (BALBINOT JUNIOR; FLECK, 2005).

De acordo com o desempenho fenológico, morfológico e agronômico de diferentes cultivares de milho, Hanashiro, Mingotte e Filho (2013), verificaram que a cultivar híbrido duplo AG 1051 obteve uma área foliar média de $671 \mathrm{~cm}^{2}$, enquanto Sá, Ramalho e Sobrinho (2002) encontraram área foliar de $549 \mathrm{~cm}^{2}$, valores superiores ao encontrado nesse trabalho, provavelmente pelo controle total das pragas dessas áreas experimentais.

Fatores podem ter interferido no crescimento das plantas, como pouca água disponível em relação à exigida pela cultura, modificando o balanço hormonal, diminuindo a alongamento e divisão celular para expan- são da área foliar, deixando as plantas vulneráveis ao ataque das lagartas. Outros fatores seriam o grau de dano ocasionado pela praga em estudo dificultando o desempenho da cultivar, bem como a disputa por nutrientes com o feijão consorciado na área. No cultivo consorciado, as espécies podem competir por energia luminosa, água e nutrientes, diferindo-se em altura entre outras características morfológicas (FLESCH, 2002).

O diâmetro do colmo apresentou diferença entre os tratamentos aos 45 DAE tendo os melhores resultados no TI e TII e, aos 70 DAE não diferiram significativamente (Tabela 2). Indicando que os tratamentos TI e TII foram os que melhor controlaram a lagarta-do-cartucho, evitando maiores danos a cultura. Além do ataque da $S$. frugiperda, o consorciamento da cultura em estudo com o feijão pode ter interferido no desenvolvimento inicial do diâmetro do colmo, principalmente nos tratamentos que não conseguiram se igualar ao TI e TII.

Em experimento com a cultura de milho consorciado com feijão, Andrade et al. (2001) e Viegas Neto et al. (2012), verificaram que a redução no diâmetro do colmo ocorreu devido à competição interespecífica com o feijão consorciado. E no trabalho de Souza (2013), dentre duas cultivares de milho (AG 1051 e BR 106) estudada, verificou que o AG 1051 destacou-se apresentando diâmetro de colmo significativamente maior com $2,33 \mathrm{~cm}$, resultados estes aproximados ao deste experimento. Mostrando que no presente trabalho, aos 45 dias o consorciamento com o feijão, pode ter atuado sobre a variável, mas que a cultivar de milho conseguiu se recuperar, não havendo influencia aos 70 DAE.

Dando sequencia aos parâmetros avaliados, o item produção levou-se em consideração comprimento, diâmetro e peso da espiga empalhada e despalhada; número de fileiras e de grãos por espiga (Tabela 3). Os tópicos comprimento longitudinal empalhada e desempalhada, não obtiveram valores significativos, com os valores variando de 26,85 a $30,90 \mathrm{~cm}$ e 16,00 a 19,15 $\mathrm{cm}$, respectivamente.

Os resultados desse trabalho foram semelhantes quando comparados aos trabalhos encontrados na literatura. $\mathrm{O}$ valor de espiga empalhada encontrado por Rocha (2008) foi em média de $27 \mathrm{~cm}$ e despalhada de $17 \mathrm{~cm}$, para cultivar AG 1051. Já Dourado Neto et al. (2003) para a mesma cultivar de milho, obteve aproximadamente o comprimento da espiga de $22 \mathrm{~cm}$, onde para o controle de $S$. frugiperda, foi utilizado uma aplicação de clorpirifós. Para a espiga despalhada desta mesma cultivar, Pereira Filho, Oliveira e Cruz (2016) e Santos et al. (2005) obtiveram um comprimento aproximado de $17 \mathrm{~cm}$. 

MILHO.

Tabela 2: Altura das plantas, número de folhas verdes na planta, área foliar e diâmetro do colmo.

\begin{tabular}{|c|c|c|c|c|c|c|c|c|}
\hline & \multicolumn{8}{|c|}{ Tempo de Avaliações (dias) } \\
\hline & 45 & 70 & 45 & 70 & 45 & 70 & 45 & 70 \\
\hline Tratamentos & \multicolumn{2}{|c|}{$\begin{array}{l}\text { Altura da planta } \\
(\mathrm{cm})\end{array}$} & \multicolumn{2}{|c|}{$\begin{array}{c}\mathrm{N}^{0} \text { de folhas verdes } \\
\text { por planta }\end{array}$} & \multicolumn{2}{|c|}{$\begin{array}{c}\text { Área foliar } \\
\left(\mathbf{c m}^{2}\right)\end{array}$} & \multicolumn{2}{|c|}{$\begin{array}{l}\text { Diâmetro do colmo } \\
(\mathbf{c m})\end{array}$} \\
\hline $\begin{array}{c}\text { Inseticida Lannate } \mathrm{BR}^{\circledR} \\
\text { e Certero }{ }^{\circledR}\end{array}$ & $153,50 \mathrm{a}$ & $194,50 \mathrm{a}$ & $14,00 \mathrm{a}$ & $12,80 \mathrm{a}$ & $493,72 \mathrm{a}$ & 375,48 a & $3,22 \mathrm{a}$ & $2,55 \mathrm{a}$ \\
\hline $\begin{array}{c}\text { Bactéria } \\
\text { Itextit }\{\text { Bacillus thuringiensis }\}\end{array}$ & $144,50 \mathrm{a}$ & $215,40 \mathrm{a}$ & $13,10 \mathrm{a}$ & $13,90 \mathrm{a}$ & $434,76 \mathrm{ab}$ & $376,28 \mathrm{a}$ & $3,18 \mathrm{a}$ & $2,63 \mathrm{a}$ \\
\hline Fertilizante Matrix & $130,85 \mathrm{a}$ & $177,95 \mathrm{a}$ & $13,60 \mathrm{a}$ & $12,30 \mathrm{a}$ & $393,69 \mathrm{~b}$ & $318,92 \mathrm{a}$ & $2,88 \mathrm{~b}$ & $2,32 \mathrm{a}$ \\
\hline $\begin{array}{l}\text { Aplicação de água - } \\
\text { testemunha }\end{array}$ & $140,30 \mathrm{a}$ & $178,05 \mathrm{a}$ & $13,75 \mathrm{a}$ & $13,40 \mathrm{a}$ & $372,32 \mathrm{~b}$ & $300,63 \mathrm{a}$ & $2,56 \mathrm{c}$ & $2,35 \mathrm{a}$ \\
\hline Teste $\mathrm{F}$ & $2,46 \mathrm{~ns}$ & $3,70 \mathrm{~ns}$ & $1,08 \mathrm{~ns}$ & $2,22 \mathrm{~ns}$ & $5,44^{*}$ & $2,71 \mathrm{~ns}$ & $20,86^{* *}$ & $1,59 \mathrm{~ns}$ \\
\hline $\mathrm{CV}(\%)$ & $7,32 \%$ & $9,63 \%$ & $5,36 \%$ & $7,39 \%$ & $10,81 \%$ & $13,77 \%$ & $4,54 \%$ & $9,83 \%$ \\
\hline
\end{tabular}

As médias seguidas pela mesma letra na coluna não diferem estatisticamente entre si.

** Significativo ao nível de $1 \%$ de probabilidade $(\mathrm{p}<0,01)$, * Significativo ao nível de $5 \%$ de probabilidade

$(0,01=<\mathrm{p}<0,05)$, ns não significativo $(\mathrm{p}>=0,05)$

Tabela 3: Variáveis relacionadas a produtividade de milho: comprimento da espiga longitudinal com palha (CEP) e sem palha (CESP) em cm; diâmetro da espiga com palha (DEP) e sem palha (DESP) em cm; peso da espiga por planta com palha (PEP) e sem palha (PESP) em g; número de fileiras da espiga (NFE) e número de grãos por espiga (NGE).

\begin{tabular}{|c|c|c|c|c|c|c|c|c|}
\hline Tratamentos & $\begin{array}{l}\text { CEP } \\
(\mathbf{c m})\end{array}$ & $\begin{array}{l}\text { CESP } \\
(\mathrm{cm})\end{array}$ & $\begin{array}{l}\text { DEP } \\
(\mathrm{cm})\end{array}$ & $\begin{array}{l}\text { DESP } \\
(\mathrm{cm})\end{array}$ & PEP (g) & PESP (g) & NFE & NGE \\
\hline $\begin{array}{l}\text { Inseticida Lannate BR }{ }^{\circledR} \\
\text { e Certero }{ }^{\circledR}\end{array}$ & 26,85 a & $16,00 \mathrm{a}$ & $5,04 \mathrm{a}$ & $4,40 \mathrm{a}$ & $318,27 \mathrm{a}$ & $200,50 \mathrm{a}$ & $15,35 \mathrm{a}$ & $548,80 \mathrm{a}$ \\
\hline $\begin{array}{l}\text { Bactéria } \\
\text { Itextit\{Bacillus thuringiensis\} }\end{array}$ & $30,35 \mathrm{a}$ & 19,15 a & $5,53 \mathrm{a}$ & 4,39 a & $322,03 \mathrm{a}$ & 201,37 a & $15,00 \mathrm{a}$ & $418,90 \mathrm{a}$ \\
\hline Fertilizante Matrix & $30,90 \mathrm{a}$ & $18,60 \mathrm{a}$ & $5,09 \mathrm{a}$ & $4,34 \mathrm{a}$ & $302,50 \mathrm{a}$ & $197,60 \mathrm{a}$ & $15,80 \mathrm{a}$ & $579,25 \mathrm{a}$ \\
\hline $\begin{array}{l}\text { Aplicação de água } \\
\text { - testemunha }\end{array}$ & $29,60 \mathrm{a}$ & $18,10 \mathrm{a}$ & $5,04 \mathrm{a}$ & 4,19 a & $296,50 \mathrm{a}$ & $178,37 \mathrm{a}$ & $15,47 \mathrm{a}$ & 556,65 a \\
\hline Teste F & $1,04 \mathrm{~ns}$ & $0,53 \mathrm{~ns}$ & $1,07 \mathrm{~ns}$ & $0,58 \mathrm{~ns}$ & $0,25 \mathrm{~ns}$ & $0,39 \mathrm{~ns}$ & $0,54 \mathrm{~ns}$ & $1,23 \mathrm{~ns}$ \\
\hline $\mathrm{CV} \%$ & $11,90 \%$ & $21,99 \%$ & $8,79 \%$ & $6,01 \%$ & $15,61 \%$ & $17,70 \%$ & $5,71 \%$ & $24,81 \%$ \\
\hline
\end{tabular}

As médias seguidas pela mesma letra na coluna não diferem estatisticamente entre si.

** Significativo ao nível de $1 \%$ de probabilidade $(\mathrm{p}<0,01)$, * Significativo ao nível de $5 \%$ de probabilidade

$(0,01=<p<0,05)$, ns não significativo $(\mathrm{p}>=0,05)$

O conhecimento do comprimento de espiga empalhada é um item importante na escolha de cultivares a serem adotadas e nas técnicas de manejo a serem empregadas no cultivo do milho-verde, e a espiga despalhada, expressando o desenvolvimento da espiga, como a capacidade de fornecimento de fotoassimilados para o crescimento e o enchimento de grãos (VIEIRA. 2007).

Com relação ao diâmetro das espigas com e sem palha, também não houve diferença estatística entre os tratamentos (Tabela 3). As espigas empalhadas apresentaram diâmetros semelhantes $(5,04$ a $5,53 \mathrm{~cm})$ aos encontrados por Vieira (2007), com quatro cultivares de milho, em cinco populações de plantas na região de Ponta Grossa - PR, onde foi obtido médias que variaram de 5,31 a $6,0 \mathrm{~cm}, 5,42$ a $6,5 \mathrm{~cm}, 5,4$ a $6,46 \mathrm{~cm}, 4,97$ a 6,43 para as cultivares Penta, 30P34, DKB 214, SWM 551, respectivamente. $\mathrm{E}$ os valores do diâmetro das espigas despalhadas $(4,19$ a 4,40 cm) são próximos aos encontrados por Santos et al. (2005), em experimentos com a variedade AG1051 onde o mesmo obteve o valor médio de $4,4 \mathrm{~cm}$ de diâmetro.

Os valores médios referentes ao peso das espigas empalhadas e despalhadas conforme Tabela 3, não houve diferença entre os tratamentos. Valores semelhantes aos deste trabalho para cultivar em questão (AG 1051) foram encontrados por diversos autores. Avaliando-se o comportamento de 5 cultivares diferentes na produção de milho, dentre elas AG 1051, Braga (2015), obteve o peso médio de espiga com palha é $312,89 \mathrm{~g}$ e $219,92 \mathrm{~g}$ para espigas sem palha, que igualmente a Rocha (2008) também analisou o comportamento de diferentes cultivares para produção de mi- 

MILHO.

lho verde constatando que as cultivares BM 3061, P 3232, AG 1051 e AG 4051 comportaram-se semelhantemente em relação à característica em estudo (peso com palha) com médias apresentadas de 319; 329; 324 e $313 \mathrm{~g} \mathrm{planta}^{-1}$, respectivamente, como também as mesmas cultivares apresentaram resultados semelhantes para peso de espiga despalhada, sendo eles $175 ; 180$; 180 e $171 \mathrm{~g} \mathrm{planta}^{-1}$, respectivamente.

As médias dos números de fileiras das espigas não diferiram estatisticamente, atingindo valores que variam de 15 a 15,80 fileiras (Tabela 3). Resultados similares aos encontrados por Vieira (2007) que trabalhando com quatro cultivares de milho, obtiveram médias superiores a 14 fileiras de grãos. O mesmo afirma que essa variável não é fator limitante a aceitação do produto no mercado. Valores similares foram encontrados por Rocha (2008) para o número de fileiras em experimento com as variedades AG 4051, AG 1051 e BM 3061 onde o mesmo obteve médias de 14 fileiras para essas cultivares.

Para o parâmetro número de grãos não houve diferença significativa entre os tratamentos (Tabela 3). Segundo Borges et al. (2014), a média do numero de grãos por espiga é de 457,73 , em solo com baixa fertilidade, valor este inferior ao desde trabalho, com exceção o do TII que apresentou uma média de 418,90. Por outro lado, Vazquez et al. (2012) ao avaliarem a influencia do tamanho e da forma da semente de milho sobre o desenvolvimento da planta e a produtividade de grãos, constataram que a média de número de grãos por espiga é de aproximadamente 620, valor este superior ao deste experimento.

Um dos fatores que pode ter levado a não diferenciação dos tratamentos estatisticamente pode ter sido a presença de inimigos naturais na área, auxiliando no controle da $S$. frugiperda, no qual ao longo das avaliações foram identificados insetos considerados como joaninhas (Coleoptera: Coccinellidae) e crisopídeos (Neuroptera: Chrysopidae), sendo maior nível de nas parcelas posteriormente as aplicações, no TIII, seguido dos TIV, TII e TI com presença dos inimigos em cerca de $16,25 \% ; 10,83 \% ; 6,67 \%$ e $5,42 \%$ referente a presença e ausência do total de plantas avaliadas por tratamento, respectivamente. Esse resultado mostra que provavelmente a adoção do controle químico inibiu o aparecimento de inimigos naturais na área de cultivo, possivelmente pela baixa seletividade ecológica ou biológica dos inseticidas Metomil (Lannate ${ }^{\circledR}$ ) e Triflumurom (Certero $\left.{ }^{\circledR}\right)$.

Os inimigos naturais podem ser fundamentais na supressão da $S$. frugiperda, de acordo com Figueiredo,
Martins-Dias e Cruz (2006), ao estudarem relação entre a lagarta-do-cartucho e seus agentes de controle biológico natural na produção de milho, relataram que a intensidade dos danos de $S$. frugiperda são elevados quando seus inimigos naturais não estão presentes na área de cultivo.

Deve-se ressaltar que os tratamentos TIII e TIV, não conseguiram serem eficientes no controle da S. frugiperda, em decorrência das plantas dessas parcelas terem sido as mais atacadas na fase inicial da cultura, sendo a fase mais crucial para o ataque da $S$. frugiperda aos 45 DAE, ocorrendo o fechamento do cartucho. No qual levando em consideração o crescimento da planta, foram os que obtiveram resultado negativo para as variáveis de área foliar e diâmetro do colmo nos primeiros 45 DAE. Porém proporcionaram melhor equilíbrio do ambiente, tornando-o propício para a presença dos inimigos naturais, levando a ocorrência de controle biológico natural da praga $S$. frugiperda, diminuindo sua intensidade. Assim, possibilitou as plantas a se recuperarem, igualando-se aos outros tratamentos, tanto na fase final de crescimento como na produção.

\section{CONCLUSÃO}

$\mathrm{O}$ tratamento químico (inseticida Lannate $\mathrm{BR}^{\circledR} \mathrm{e}$ Certero $^{\circledR}$ ) e biológico (bactéria $B$. thuringiensis) apresentaram melhor resposta para os parâmetros área foliar e diâmetro do colmo no crescimento das plantas aos 45 DAE, evitando maiores impactos da lagarta-docartucho na cultura. Nas varáveis de produção todos os tratamentos se comportaram de forma igualitária, mostrando que características padrões não foram afetadas, onde os inimigos naturais presentes na área experimental influenciaram positivamente para tal resultado e equilíbrio do ambiente.

\section{AGRADECIMENTOS}

Instituto Federal de Educação, Ciência e Tecnologia do Ceará (IFCE); Conselho Nacional de Desenvolvimento Científico e Tecnológico (CNPq); Companhia do Milho Verde; Empresa Bio Controle; Universidade Federal Rural do Semiárido (UFERSA); Global Crops; Terra Fértil; Agrovale; Fapija; Consegurança; Engenheiro Agrônomo Allison Rafael Felino Leitão.

\section{REFERÊNCIAS}

ANDRADE, M.; MORAIS, A.; TEIXEIRA, I. R.; SILVA, M. Avaliação de sistemas de consórcio de feijão com milho pipoca. Ciência e Agrotecnologia, v. 25, n. 2, p. 242-250, 2001. 
INFLUÊNCIA DOS MÉTODOS DE CONTROLE DA LAGARTA-DO-CARTUCHO SOBRE O DESENVOLVIMENTO E PRODUÇÃO DE MILHO.

BALBINOT JUNIOR, A. A.; FLECK, N. G. Redução do espaçamento entre fileiras: benefícios e limitações. Plantio Direto, v. 5, n. 87, p. 37-41, 2005.

BARBOSA, T. G.; VASCONCELOS, R. C.; VIANA, A. E. S.; BORGES, I. D.; SOUSA, D. Q. Características agronômicas de cultivares de milho a diferentes populações de plantas na safrinha em vitória da conquista - ba. In: XXIX Congresso Nacional de Milho e Sorgo. Águas de Lindóia: CNMS, 2012. p. 1869-1874.

BORGES, T. K. d. S.; MONTENEGRO, A. A. d. A.; SANTOS, T. E. M. d.; SILVA, D. D. d.; JUNIOR, V. d. P. S. Influência de práticas conservacionistas na umidade do solo e no cultivo do milho (zea mays 1.) em semiárido nordestino. Revista Brasileira de Ciência do Solo, SciELO Brasil, v. 38, n. 6, p. 1862-1873, 2014.

BRAGA, A. H. Produtividade de cultivares de milho para silagem em duas épocas de cultivo em Cáceres. Dissertação (Graduaçao em Agronomia) Universidade do Estado de Mato Grosso - Campus de Cáceres, Cáceres, MT, 2015. 18 f.

CHAVES, F. F.; CALSAVARA, L. H. F.; SOBRINHO, J. G.; OLIVEIRA, A. de; NOCE, M.; CARVALHO, D. d. O.; PESSOA, S. Manejo integrado da lagarta-do-cartucho (spodoptera frugiperda) do milho em sistema de integração lavoura-pecuária (ilp). In: XXIX Congresso Nacional de Milho e Sorgo. Águas de Lindóia: CNMS, 2012. p. 1013-1019.

CONAB. Acompanhamento da safra brasileira de grãos. Brasil, 2016. Agencia Prodetec. Disponível em: <http://www.agenciaprodetec.com.br/inicio/ 923-nordeste-expectativa-para-o-milho-em-2017-I e-de-uma-safra-53-maior.html>.

CRUZ, S. J. S. Características morfofisiológicas de plantas e produtividade do milho. Tese (Doutorado em Agronomia) — Faculdade de Ciências Agronômicas da UNESP - Campus de Botucatu, Botucatu, 2013. $77 \mathrm{f}$.

DAVIS, F. M.; WILLIAMS, W. P.; WISEMAN, B. R. Methods used to screen maize for and to determine mechanisms of resistance to the southwestern corn borer and fall armyworm. In: International Symposium on Methodologies for Developing Host Plant Resistance to Maize Insects. Mexico, DF (Mexico). 9-14 Mar 1987. México: Proceedings, 1989. p. 101-108.
DNOCS. Chapada do Apodi. Ceará, 2015. Disponível em: <http://www.dnocs.gov.br/ dnocs/doc/canais/ perimetros_irrigados/ce/jaguaribe_apodi.html>

Dourado Neto, D.; PALHARES, M.; VIEIRA, P. A.; MANFRON, P. A.; MEDEIROS, S. L. P.; ROMANO, M. R. Efeito da população de plantas e do espaçamento sobre a produtividade de milho. Revista Brasileira de Milho e Sorgo, v. 2, n. 03, p. 63-77, 2003.

DUARTE, J. O.; CRUZ, J. C.; GARCIA, J. C.; MATTOSO, M. J. Economia da produção. In: C., C. J. (Ed.). Cultivo do milho. Sete Lagoas, 2010. Disponível em: <http://www.cnpms.embrapa.br/ publicacoes/milho_6_ed/economia.htm>

ELINGS, A. Estimation of leaf area in tropical maize. Agronomy Journal, American Society of Agronomy, v. 92, n. 3, p. 436-444, 2000.

EMBRAPA. Risco potencial das pragas de milho e de sorgo no Brasil. Sete Lagoas - MG, 2013. Julho. Disponível em: <http: //www.embrapa.br/alerta-helicoverpa/Doc150.pdf>

FANCELLI, A. L.; NETO, D. D. Produção de milho. Agropecuária, v. 18, n. 1, p. 360, 2000.

FIGUEIREDO, M. d. L. C.; MARTINS-DIAS, A. M. P.; CRUZ, I. Relação entre a lagarta-do-cartucho e seus agentes de controle biológico natural na produção de milho. Pesquisa Agropecuária Brasileira, SciELO Brasil, v. 41, n. 12, p. 1693-1698, 2006.

FLESCH, R. D. Efeitos temporais e espaciais no consórcio intercalar de milho e feijão. 1. ed. Brasília, 2002. 51-56 p.

GALZER, E. C. W.; FILHO, W. S. A. Utilização do bacillus thuringiensis no controle biológico de pragas. Revista Interdisciplinar de Ciência Aplicada, v. 1, n. 1, p. 13-16, 2016.

HANASHIRO, R. K.; MINGOTTE, F. L. C.; FILHO, D. F. Desempenho fenológico, morfológico e agronômico de cultivares de milho em jaboticabal-sp. Científica, v. 41, n. 2, p. 226-234, 2013.

IBGE (Ed.). Levantamento sistemático da produção agrícola, v. 29, n. 1. Rio de Janeiro: Instituto Brasileiro de Geografia e Estatística (IBGE), 2016. 1-78 p.

MAPA. Sistema de Agrotóxicos Fitossanitários. Brasília, 2016. Disponível em: <http://www. agricultura.gov.br/>. 

MILHO

OECD. OECD-FAO Agricultural Outlook 2015. Paris, 2015. Disponível em: <http: //dx.doi.org/10.1787/agr_outlook-2015-en>.

Pereira Filho, I. A.; OLIVEIRA, A. C.; CRUZ, J. C. Milho verde: espaçamentos, densidades de plantas, cultivares e épocas de semeadura influenciando o rendimento e algumas características do espigas comerciais. In: IN: CONGRESSO NACIONAL DE MILHO E SORGO, 22., 2016, RECIFE. GLOBALIZAÇÃO E SEGURANçA ALIMENTAR:. Embrapa Milho e Sorgo-Artigo em anais de congresso (ALICE). Recife, 2016.

PEREIRA, L. G. B. Táticas de Controle da Lagarta-do-Cartucho do Milho, Spodoptera frugiperda. 2007. Fundação Centro Tecnológico de Minas Gerais CETEC. Dossiê técnico.

ROCHA, D. R. Desempenho de cultivares de milho-verde submetidos a diferentes populações de plantas em condições de irrigação. Tese (Doutorado em Agronomia) — Faculdade de Ciências Agrárias e Veterinárias - Unesp, Jaboticabal, 2008. 106 f.

ROSA, A. P. S. A. d. Monitoramento da lagartado-cartucho do milho. 2011. Empresa Brasileira de Pesquisa Agropecuária.

SÁ, M. d.; RAMALHO, M.; SOBRINHO,

F. d. S. Aspectos morfológicos e fisiológicos de cultivares modernas e antigas de milho. Ciência e Agrotecnologia, v. 26, n. 5, p. 1082-1091, 2002.

SANTOS, I. C.; MIRANDA, G. V.; MELO, A. V.; MATTOS, R. N.; OLIVEIRA, L. R.; LIMA, J. S.; GALVãO, C. C. Comportamento de cultivares de milho produzidos organicamente e correlações entre características das espigas colhidas no estádio verde. Revista Brasileira de Milho e Sorgo, v. 4, n. 1, p. 45-53, 2005.

SILVA, F. ASSISTAT: Versão 7.7 beta. DEAGCTRN-UFCG - Atualizado em 01 de abril de 2014. 2014. Disponível em: <http://www.assistat.com/>

SOUZA, I. A. F. Desenvolvimento e produção de milho e feijão-caupi em cultivo orgânico. Dissertação (Mestrado) - Universidade Estadual do Norte, Campos dos Goytacazes - RJ, 2013.

VAZQUEZ, G. H.; ARF, O.; SARGI, B. A.; PESSOA, A. C. O. Influência do tamanho e da forma da semente de milho sobre o desenvolvimento da planta e a produtividade de grãos. Bioscience Journal, Universidade Federal de Uberlândia (UFU), v. 28, n. 1, p. 16-24, 2012.

Viegas Neto, A. L.; HEINZ, R.; GONÇALVES, M. C.; CORREIA, A. M. P.; MOTA, L. H. d. S.; ARAÚJO, W. D. Milho pipoca consorciado com feijão em diferentes arranjos de plantas. Pesquisa Agropecuária Tropical, SciELO Brasil, v. 42, n. 1, p. 28-33, 2012.

VIEIRA, M. d. A. Cultivares e populações de plantas na produção de milho verde. Dissertação (Mestrado em Fitotecnia) — Universidade Federal do Paraná, Curitiba - PR, 2007. $95 \mathrm{f}$. 